\title{
IDENTIFICATION OF CHROMOBACTERIUM VIOLACEUM BY MALDI-TOF MASS SPECTROMETRY IN BLOOD CULTURE
}

\author{
Max Roberto Batista Araújoํ, Vanessa Wolf ${ }^{2}$, Luisa Ferreira Seabra ${ }^{1}$
}

Clin Biomed Res. 2018:38(3):308-310

1 Núcleo Técnico Operacional, Setor de Microbiologia, Instituto Hermes Pardini. Vespasiano, MG, Brasil.

2 Departamento de Microbiologia, Instituto de Ciências Biológicas, Universidade Federal de Minas Gerais (UFMG). Belo Horizonte, MG, Brasil.

Corresponding author: Max Roberto Batista Araújo max_barau@hotmail.com Instituto Hermes Pardini Av. das Nações, 2448, Santo Antônio. 33200-000, Vespasiano, MG, Brasil.

\section{ABSTRACT}

Report of Chromobacterium violaceum isolation from blood culture. Identification by MALDI-TOF mass spectrometry. Relevant report due to the site affected, infection severity, and importance of correct and rapid identification for a successful treatment and lower risk of morbidity and mortality.

Keywords: Chromobacterium; blood culture; sepsis; spectrometry, mass, matrix-assisted laser desorption-ionization

Chromobacterium violaceum is the only variety that possesses the Chromacterium gene, which in turn, belongs to the family Neisseriaceae. This microorganism is a Gram-negative, motile and facultative anaerobic bacillus, which presents a better growth below $37^{\circ} \mathrm{C}$, and has mainly soil and water of tropical and subtropical areas as habitats. Most colonies produce a distinctive violet pigment called violacein ${ }^{1}$. This pathogen grows readily on commonly used laboratory media such as sheep blood agar, MacConkey agar, and nutrient agar. Non-pigmented strains showing higher virulence and pathogenicity have been identified (Figure 1), hence the importance of not using violet pigmentation as the sole criterion for separating $C$. violaceum from other Gram-negative bacteria, in particular, Aeromonas spp and Vibrio spp, to avoid misdiagnosis ${ }^{2}$.

Human infections caused by C. violaceum are rare, being the skin the main gateway. Moreover, there are reports of severe septicemia associated with multiple abscesses in the liver, spleen, lungs, and brain, progressing to toxemia, mental confusion, shock, and death ${ }^{3-5}$.

C. violaceum is usually resistant to several antibiotics, although it is often susceptible to Imipenem, Fluoroquinolones, Gentamycin, Tetracycline and Sulfamethoxazole Trimethoprim ${ }^{1}$.

Therefore, because it is a serious disease, rapid identification and communication with the responsible clinician are relevant and critical. The aim of this study was to present a case report of $C$. violaceum in blood culture.

\section{CASE REPORT}

A 54-year-old man, resident of a municipality in the country of the state of São Paulo, with hepatitis $C$ and axillary abscess due to depilation, presented fever and pain. He went through a dermatologist who chose not to drain the abscess and prescribed Cephalexin every 8 hours. There was no improvement in the condition, so outpatient care and hospitalization occurred. The fever was maintained and the patient was then submitted to abscess drainage and use of Cephalexin every 6 hours. A culture of the material removed from the abscess was not performed.

This was a case report study. The identification was further confirmed by MALDI-TOF MS (VITEK ${ }^{\circledR}$ MS - bioMérieux ${ }^{\circledR}$, France) and patient data were obtained and discussed among the professionals involved. The Identification score was provided by middleware MYLA (bioMérieux ${ }^{\circledR}$, France). For MALDI-TOF MS analysis, protein extracts were prepared from bacterial isolates grown on a blood agar plate (BAP) (bioMérieux ${ }^{\circledR}$, Brazil) for $24 \mathrm{~h}$ at $37^{\circ} \mathrm{C}$ and suspended in $10 \%$ of formic acid (bioMérieux ${ }^{\circledR}$, Brazil). One microliter of the mixture was 


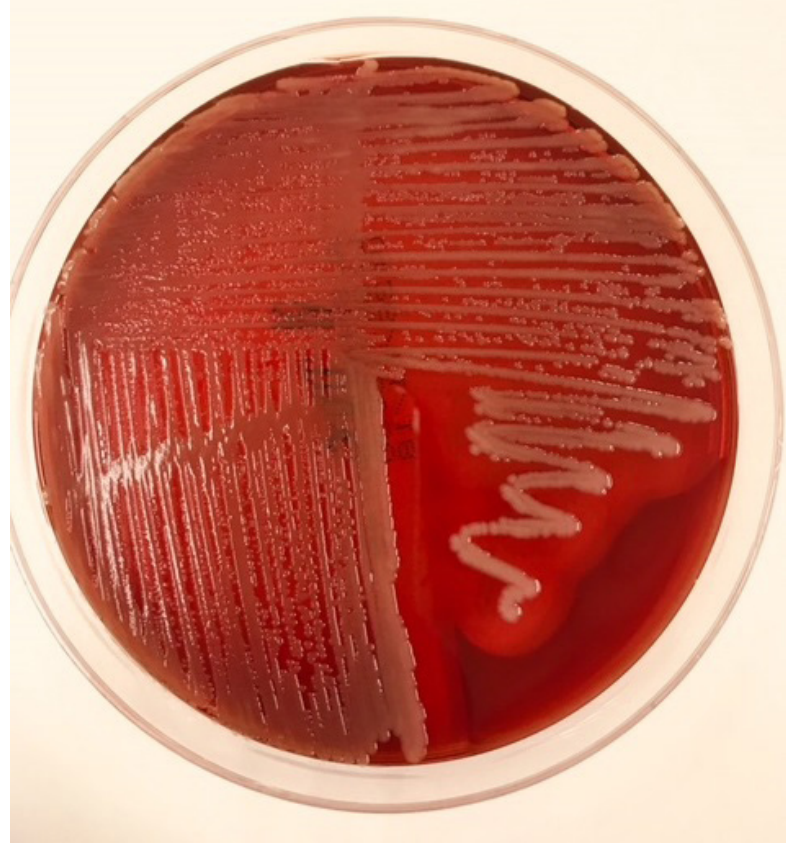

Figure 1: Non-pigmented Colonies of $C$. violaceum on a blood agar plate.

spotted onto a polished steel target plate (bioMérieux ${ }^{\circledR}$, Brazil) and air-dried. Then $1 \mu$ of a saturated solution of $\alpha$-cyano-4-hydroxycinnamic acid in acetonitrile $50 \%$ and trifluoroacetic acid $2.5 \%$ (bioMérieux ${ }^{\circledR}$, Brazil) was added and the mixture was allowed to cocrystallize at room temperature.

The patient's condition worsened and he was submitted to induced coma, with intubation and the development of hepatic and pulmonary abscesses. The medication was changed to Piperacillin-Tazobactam and Meropenem; however, there were no signs of improvement.

A blood culture sample was collected and incubated in BacT/ALERT ${ }^{\circledR}$ system (bioMérieux ${ }^{\circledR}$, France). The automated system indicated that the blood culture vial presented growth. An aliquot of the blood vial was plated onto a BAP (bioMérieux ${ }^{\circledR}$ ), which was incubated at $37^{\circ} \mathrm{C}$. The BAP (bioMérieux ${ }^{\circledR}$ ) presented growth of mucoid and violet colonies, looking different from those usually identified in the laboratory routine (Figure 2).

These colonies were plated in chromogenic medium (Chrom CPS Elite, bioMérieux ${ }^{\circledR}$, Brazil) to better visualize the violet color already suggestive of Chromobacterium violaceum (Figure 3 ).

The colonies were assessed using the $\mathrm{VITEK}^{\circledR} 2$ Compact (bioMérieux ${ }^{\circledR}$, France) automated system, which identified them as C. violaceum $(99 \%$ of probability). The identification was further confirmed

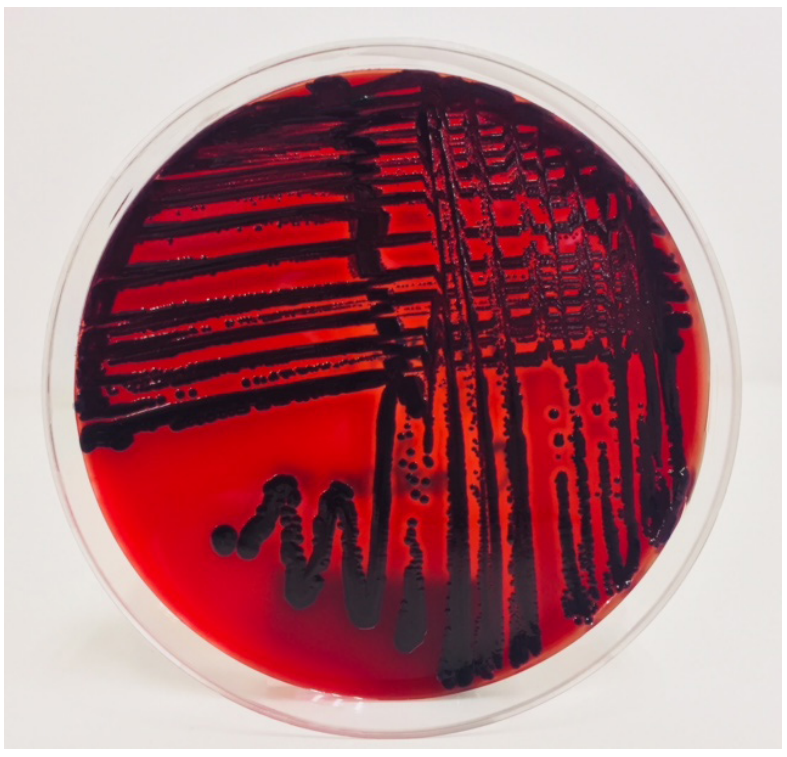

Figure 2: Colonies of $C$. violaceum on a blood agar plate.

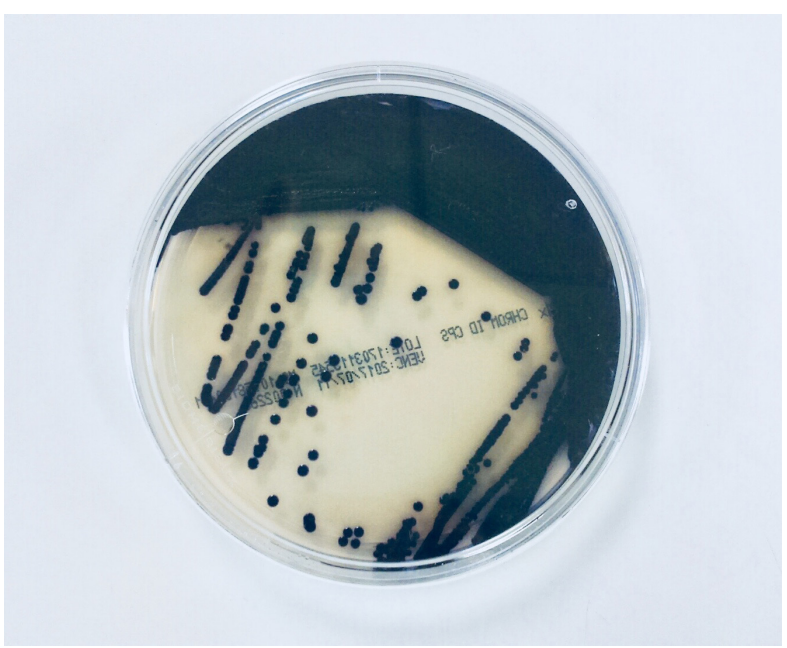

Figure 3: Colonies of $C$. violaceum on a chromogenic agar plate.

by MALDI-TOF MS (VITEK ${ }^{\circledR}$ MS), as depicted by a characteristic protein fingerprint of $C$. violaceum.

The result was immediately reported to the clinician in charge who changed the treatment to Amikacin due to information transmitted and discussed. The antibiogram was performed using the disc diffusion method, but the report was not released since the standardization guideline for antibiograms in use in the laboratory does not have an interpretation for this microorganism. We performed the antibiogram to verify the existence or not of some halo of inhibition. 


\section{DISCUSSIONS}

C. violaceum is considered an emergent pathogen. It has a propensity to develop into fatal septicemia unless appropriately treated ${ }^{6}$.

The presence of $C$. violaceum in clinical samples in a laboratory should be well evaluated. Indeed, it is a rarer species, therefore an accurate diagnosis is necessary, as well as the report to the clinician responsible for appropriate actions.

For the patient in question, it can be assumed that the infection originated from an axillary wound that generated the abscess.
Therefore, as the patient did not respond to the therapies initially adopted, it was decided to use intravenous Amikacin, an aminoglycoside, as well as Gentamicin, which is indicated for infection by the bacterium in question ${ }^{1}$.

There was a satisfactory outcome, the patient presented significant signs of improvement, being able to leave the hospital and be discharged.

\section{Conflicts of Interest}

The authors declare no conflicts of interest.

\section{REFERENCES}

1. Murray PR, Baron EJ, Jorgensen JH, Landry ML, Pfaller MA. Manual of clinical microbiology. 9. ed. Vol. 1. Washington: ASM Press; 2007. p. 624-625.

2. Teoh AY, Hui M, Ngo KY, Wong J, Lee $\mathrm{KF}$, Lai PB. Fatal septicemia from Chromobacterium violaceum: case reports and review of the literature. Hong Kong Med J. 2006;12(3):228-31. PMid:16760554.

3. Chen CH, Lin LC, Liu CE, Young TG. Chromobacterium violaceum bacteremia: a case report. J Microbiol Immunol Infect. 2003;36(2):141-4. PMid:12886967.

4. Kaufman SC, Ceraso D, Schugurensky A. First case report from Argentina of fatal septicemia caused by Chromobacterium violaceum. J Clin Microbiol. 1986;23(5):956-8. PMid:3711283.

5. Martinez R, Velludo MASL, Santos VR, Dinamarco PV. Chromobacterium violaceum Infection in Brazil. A case report. Rev Inst Med Trop São Paulo. 2000;42(2):111-3. http://dx.doi.org/10.1590/S003646652000000200008. PMid:10810326.

6. Bichitrananda S, Sarita O, Kundan KS, Kirtika P, Subhrajita R. Urinary tract infection by Chromobacterium violaceum. Journal of Clinical and Diagnostic Research. 2014;8(8):DD01-DD02. http://dx.doi. org/10.7860/JCDR/2014/9230.4703.

Received: July 12, 2018 Accepted: Sept 18, 2018 